\title{
Serious Leisure Inventory and Measurement (Short Form): Validity and Reliability Analysis
}

\section{Ali Selman Özdemir ${ }^{\circledR}$ (iD Tebessüm Ayyildiz Durhan² Beyza Merve Akgül ${ }^{3}$}

'Department of Recreation, School of Physical Education and Sport, Cyprus International University, Nicosia, Cyprus.

Email:ordemiraliselman@gmail.com

${ }^{2, s}$ Department of Recreation, Faculty of Sports Sciences, Gazi University, Ankara, Turkey.

\section{Abstract}

The aim of this study is to provide the validity and reliability analysis of the "Serious Leisure Inventory and Measurement (Short Form)" SLIM and introduce it to the literature. The data obtained from 285 university students and the KMO-Barlett test was performed and the sample size was tested $(.89 ; 2506.309, \mathrm{p}<0,001)$. A three subdimensions of structure was obtained by exploratory factor analysis. According to the exploratory factor analysis, the cut-off value was determined as .40 , a total of 18 items were converted into a 12-item form by subtracting the loadbearing substances from the measuring instrument, and factor loads of three sub-dimensions were obtained between .55 and .83 . In addition to the factor analysis results, $65 \%$ of the total variance was obtained, internal consistency coefficients were taken, respectively $.83, .84$ and .75 were found for each sub-dimension. The total internal reliability coefficient was found to be .88 . Confirmatory factor analysis was performed to test the validity and accuracy of the structure obtained after the exploratory factor analysis with 350 students. It is observed that the CFA performed after the test retest constitutes evidence for the structure validity (RMSEA .069, SRMR 0.60, NFI 0.94, CFI 0.96 , GFI $0.94, \mathrm{x} 2 / \mathrm{df} 2.42$ ). As a result, a valid and reliable measurement tool for serious leisure has been introduced.

Keywords: Leisure, Serious leisure, Scale development.

Citation | Ali Selman Özdemir; Tebessüm Ayyildiz Durhan; Beyza Merve Akgül (2020). Serious Leisure Inventory and Measurement (Short Form): Validity and Reliability Analysis. Asian Journal of Education and Training, 6(2): 207-2 12

History:

Received: 30 December 2019

Revised: 10 February 2020

Accepted: 16 March 2020

Published: 6 April 2020

Licensed: This work is licensed under a Creative Commons Attribution 3.0 License (oc) Er

Publisher: Asian Online Journal Publishing Group
Acknowledgement: All authors contributed to the conception and design of the study.

Funding: This study received no specific financial support

Competing Interests: The authors declare that they have no conflict of interests.

Transparency: The authors confirm that the manuscript is an honest, accurate, and transparent account of the study was reported; that no vital features of the study have been omitted; and that any discrepancies from the study as planned have been explained.

study as planned have been explained.
Ethical: This study follows all ethical practices during writing.

\section{Contents}

1. Introduction ........................... 208

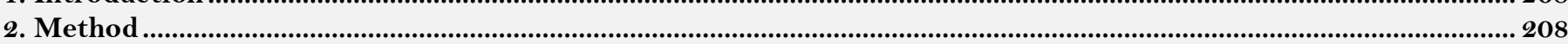

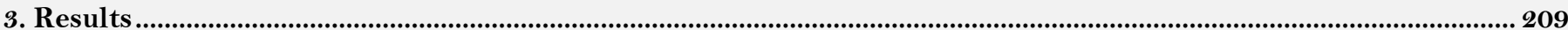

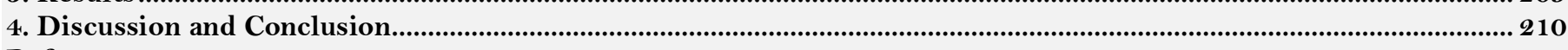

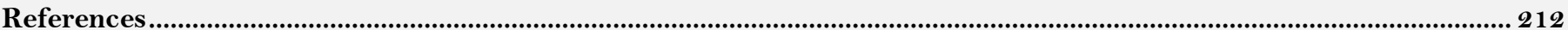




\section{Contribution of this paper to the literature}

This study is one of the very few studies which have investigated serious leisure measurement in Turkey and it contributes to the existing literature as the short form of the previous serious leisure inventory and measurement tool published in Turkey before by the authors.

\section{Introduction}

Serious leisure can be defined as a theoretical framework that synthesizes the three main forms of leisure activities by simultaneously exhibiting their distinctive features, similarities and mutual relationships, and expressing them by acquiring a combination of special talent, knowledge and experience, one of the two varieties of serious engagements. It is a systematic search for an amateur, hobbyist or a volunteer career, as important, interesting and satisfying for him. The adjective "serious" here includes traits such as sincerity and attention rather than seriousness, distress or anxiety (Stebbins, 2016). Serious leisure; it has brought a new dimension to today's world, where leisure activities will no longer be considered only leisure activities. It enabled us to elaborate leisure activities (Göklemen, 2019; Işık, 2014).

The definition of "serious leisure" being used in the studies may be; the development of skills and knowledge, the amassing of experience and the exertion of effort in a leisure activity, pursued for the aspirations of improvement and achievement of self-actualization, social belonging and / or lasting physical benefits (Geoffrey \& Currie, 1998). Serious leisure envisions leisure; as 'not fun' allows leisure to escape the conceptual burdens of enjoyment, freedom and celebrations of choice (Rojek, 1995).

Perseverance and persistence, effort, leisure career, permanent acquisitions, specific norms and identification with occupation are among the distinguishing features of serious leisure participation (Gould, Moore, McGuire, \& Stebbins, 2008; Ișık, 2014; Stebbins., 1982; Stebbins.. 1992; Stebbins... 2001). Considering the main activities of a serious leisure participant, learning the bronze, silver and gold level figures about salsa, participating in workshops on partner-work and shine steps, costume, CD, DVD etc. It should include activities such as shopping about dance materials and music, participating in various competitions and certificate programs, making a significant effort to progress, and being in a social group of dancer profiles (Akyıldız, 2013).

The distinctive features of serious leisure participants are intertwined. The participant ensured the continuity of participation in the activity he chose thanks to the social environment, and this continuity returned to him as a personal and social benefit. In order to increase this benefit even more; by making a personal effort, he tended to have a broader knowledge of the activity. The activity he has chosen has now become a part of his life, and his appointments and life have started to be adjusted according to the time he did not do this activity (Işsk, 2014).

When determining the dimension of perseverance, which is one of the distinguishing features of serious leisure participation, is the persistence of leisure activity. While leisure participants often get happy memories and pleasant memories from the activity they participate in, they may be exposed to tensions such as stage excitement and fear, sense of shame, freezing cold weather, anxiety and anxiety, fatigue and disability, and so on. For this reason, adhering to an activity is about gaining positive emotions and dealing with the difficulties of that activity and persevere. Going over the danger, supporting a losing team, persevering to cope with the difficulties of an activity or a problem faced are an important feature of serious leisure. In the personal efforts sub-dimension, it is to develop knowledge, experience, training level or skill about the activity involved and make a considerable personal effort for this. Continuous personal efforts in acquiring manual skills, scientific knowledge, speaking skills, good experience, performing art, athletic power, or the like distinguish serious leisure participants from beginner or other leisure participants (Akyıldız, 2013).

Looking at the success of his leisure career by making progress in the activity he participated in; As a result of effort and struggle, it is to get a career in activity Efforts and struggles are about reaching milestones by enduring the difficulties arising from the nature of the activity, achieving a career by gradually achieving success (Akyldiz, 2013). Leisure activities such as participation in extracurricular activities, participation in social gatherings, chances of physical exercise, participation in amateur sports organizations, participation in volunteering practices, participation in non-governmental organizations, professional experience, part-time or summer vacation employment can be used for serious leisure activities, are important mediators of the leisure career (Loughead, 1989).

The individual gain arises as a result of each individual's interest in a particular pursuit, unlike the broadly qualified global order hidden in the content of the gains. Personal enrichment is an accumulation of loving and valued experiences that arise as a result of serious participation with the increase of one's spiritual resources. Full utilization of one's capacity, talents and potential is defined as self-realization. This means that the person develops and applies his unique talents, skills and knowledge in serious pursuits. Participants not only apply their talents, skills and knowledge, but also express them. The expression of these skills is complementary to the acquisition of self-expression; Another complement is related to the way the person expresses his individuality (Göklemen, 2019).

Through the distinctive features of serious leisure participation, a general belief is formed regarding the serious leisure situations of individuals. Determining serious leisure perspectives gained importance at this point by means of effective and efficient measurement tools. In measuring the area and property to be measured; It is aimed to clarify the serious leisure which has an important place in the field by starting from the necessity of creating a questionnaire forms with a suitable solution containing a sufficient number of items. In this direction, a short form of leisure assessment was created based on the best functioning items in the serious leisure scale and validity and reliability analyzes were included in the research.

\section{Method}

The data were obtained through voluntary participation of 593 participants studying at Gazi University, Cyprus International University, Ankara University and Bülent Ecevit University during 2019-2020 academic year. The data were collected by using test-retest method. In the first phrase, the final form was created after exploratory factor analysis was performed in the light of the data obtained from 285 participants and the retest was 
applied to 305 participants through the final version of the form. Confirmatory factor analysis was performed with the data obtained. The data were evaluated in the SPSS 23 package program and the sample group $(.88, \mathrm{p}<0.001)$ is sufficient in size according to the results of Kaiser-Meyer-Olkin (KMO) and Barlett tests performed to test whether the size of the sample group is sufficient or not. The factor loading of the data and the variance values were identified by using exploratory factor analysis, as well as the internal reliability coefficients were calculated for each factor. The phase of the confirmatory factor analysis was initiated through the Lisrel 8.7 package program to confirm the final version of the form. The findings on the analysis are given below.

\section{Results}

Table-1. KMO and Barlett's test results.

\begin{tabular}{l|c|c}
\hline \multicolumn{1}{l|}{ KMO and Bartlett's Test } & 0,893 \\
\hline Kaiser-Meyer-Olkin Sample Group Size & & 2506,309 \\
\hline Barlett Sphericity Test & $\mathrm{x}^{2}$ & 153 \\
\hline & $\mathrm{sd}$ & 0,000 \\
\hline
\end{tabular}

When the Table 1 is examined, the test results for the adequacy of the Kaiser Meyer Olkin Sample Group and the Barlett's Test of Sphericity results show that the sample group is sufficient to analyze $(.89 ; 2506.309, \mathrm{p}<0.001)$.

\begin{tabular}{|c|c|c|c|c|c|c|c|}
\hline & & Items & I. & II. & III. & $\begin{array}{c}\text { Cronbach } \\
\text { Alpha }\end{array}$ & $\begin{array}{l}\text { Explained } \\
\text { Variance }\end{array}$ \\
\hline \multirow{5}{*}{$\begin{array}{l}\text { Identification } \\
\text { with pursuit } \\
\text { and Social } \\
\text { outcomes }\end{array}$} & $\begin{array}{l}\text { I enjoy interacting with other } \\
\ldots \ldots \ldots \ldots \ldots \ldots \text { enthusiasts. }\end{array}$ & 14 & 0.691 & & & & $\% 25.96$ \\
\hline & $\begin{array}{l}\text { I feel important when I am a part } \\
\text { of my } \ldots \ldots \ldots \ldots \ldots \ldots \text { group's } \\
\text { accomplishments. }\end{array}$ & 15 & 0.809 & & & 0.83 & \\
\hline & $\begin{array}{l}\text { It is important that I perform } \\
\text { duties which unify my } \\
\ldots \ldots \ldots \ldots \ldots \ldots \text { group. }\end{array}$ & 16 & 0.837 & & & & \\
\hline & $\begin{array}{l}\text { I share many of my } \ldots \ldots \ldots \ldots \ldots \ldots \\
\text { group's ideals. }\end{array}$ & 17 & 0.777 & & & & \\
\hline & $\begin{array}{l}\text { Others that know me understand } \\
\text { that } \ldots \ldots \ldots \ldots \ldots \ldots \text { is a part of } \\
\text { who I am. }\end{array}$ & 18 & 0.550 & & & & \\
\hline \multirow{4}{*}{$\begin{array}{l}\text { Perseverance } \\
\text { and Leisure } \\
\text { career }\end{array}$} & $\begin{array}{l}\text { I overcome difficulties in } \\
\ldots \ldots \ldots \ldots \ldots \ldots \text { by being persistent. }\end{array}$ & 1 & & 0.821 & & 0.84 & $\% 22.46$ \\
\hline & $\begin{array}{l}\text { I try hard to become more } \\
\text { competent in } \ldots \ldots \ldots \ldots \ldots \ldots \ldots\end{array}$ & 2 & & 0.790 & & & \\
\hline & $\begin{array}{l}\text { I feel that I have made progress in } \\
\ldots \ldots \ldots \ldots \ldots \ldots\end{array}$ & 3 & & 0.775 & & & \\
\hline & $\begin{array}{l}\text { There are defining moments } \\
\text { within } \ldots \ldots \ldots \ldots \ldots \ldots \text { that have } \\
\text { significantly shaped my } \\
\text { involvement in it. }\end{array}$ & 4 & & 0.627 & & & \\
\hline \multirow[t]{4}{*}{$\begin{array}{l}\text { Individual } \\
\text { outcomes }\end{array}$} & $\begin{array}{l}\text {................ has added richness } \\
\text { to my life. }\end{array}$ & 5 & & & 0.656 & 0.75 & $\% 18.32$ \\
\hline & $\begin{array}{l}\text {.............. for me is an } \\
\text { expression of myself. }\end{array}$ & 8 & & & 0.830 & & \\
\hline & $\begin{array}{l}\text { I think about myself. } \\
\text { I }\end{array}$ & 9 & & & 0.798 & & \\
\hline & & Total & & & & 0.88 & $\% 65.76$ \\
\hline
\end{tabular}

In line with the exploratory factor analysis in Table 2 , the cutoff value was determined as .40 and moreover, a pool of questions consisting of 18 items in total has been reduced to 12 items by removing some of them from the scale as the $13^{\text {th }}$ item was in negative value, the $6^{\text {th }}$ and the $7^{\text {th }}$ items imposed burden to other items, and the $10^{\text {th }}$, the $11^{\text {th }}$ and $12^{\text {th }}$ items compromised of the sub-items less than 3 . The items with factor load between .55 and .83 were collected in 3 sub-dimensions. Internal consistency coefficients were determined as .83 for the first factor, .84 for the second factor, and .75 for the third factor, and .88 for the entire scale. The proportion of explained variance is $65 \%$ in the total variance and $24.96 \%$ for the first factor, $22.46 \%$ for the second factor and $18.32 \%$ for the third factor. 


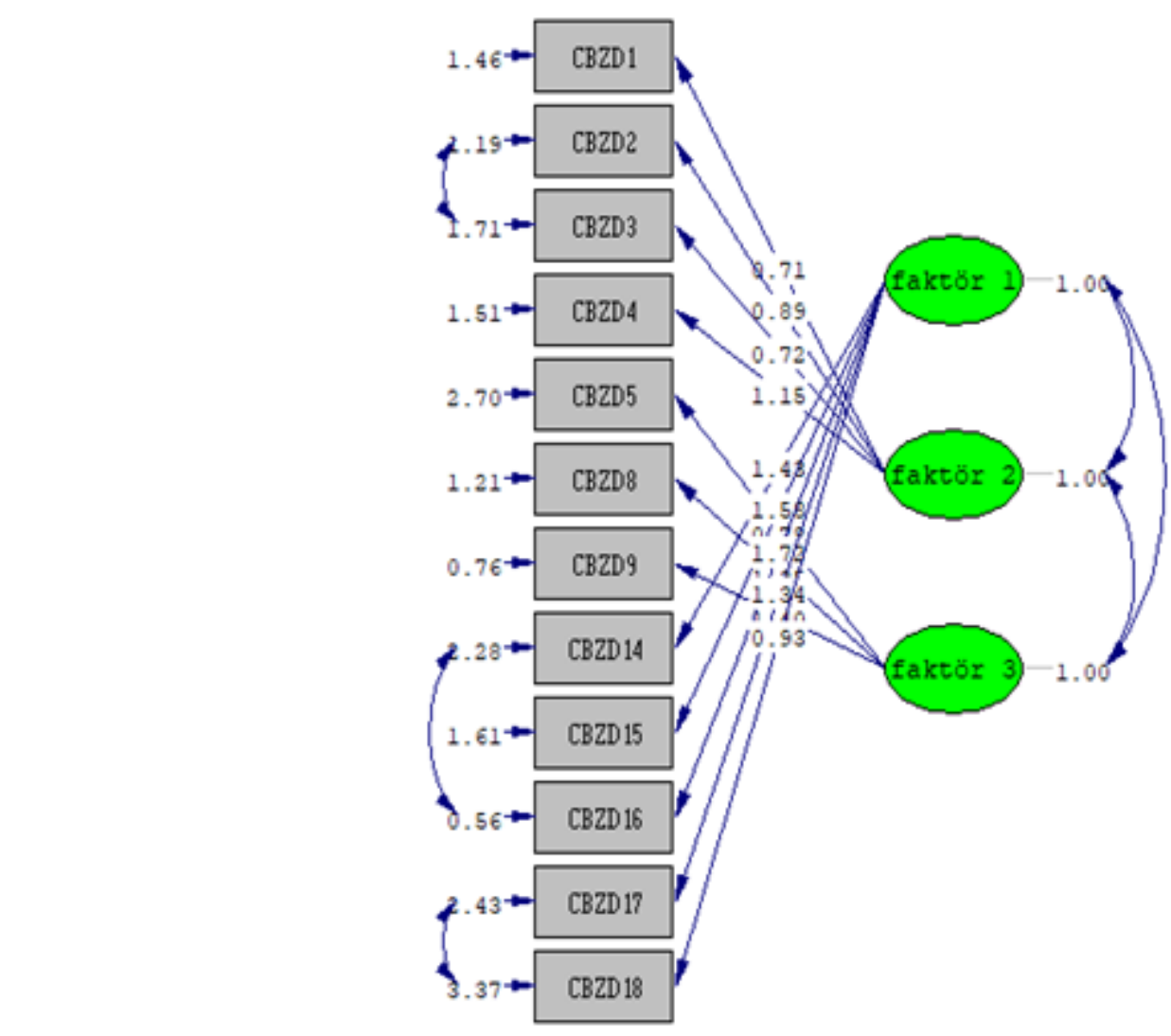

Chi-Square=116.54, df $=48$, P-value $=0.00000$, RMSEA $=0.069$

Figure-1. Confirmatory factor analysis' diagram.

In Figure 1, confirmatory factor analysis was performed to test the validity and the accuracy of the tool created after the exploratory factor analysis. It is thought that DFA performed after test-retest provides evidence of the validity for the tool (RMSEA .069, SRMR 0.60, NFI 0.94, CFI 0.96, GFI 0.94, x2 / df 2.42).

Table-3. Fit indices and model fit for limit values.

\begin{tabular}{c|c|c|c|c}
\hline Fit Index & Ideal fit values & Acceptable values & Incompatible & Values obtained \\
\hline RMSEA & $0-0.05$ & $0.05-0.09$ & $>0.10$ & 0.69 \\
\hline CFI & 1 & $0.90-0.99$ & $<0.90$ & 0.96 \\
\hline GFI & 1 & $0.90-0.99$ & $<0.90$ & 0.94 \\
\hline $\mathrm{x}^{2} / \mathrm{df}$ & $<=2$ & $2-5$ & $5+$ & 2.42 \\
\hline
\end{tabular}

Note: Erkorkmaz, Etikan, Demir, Özdamar, and Sanisaoğlu (2013).

Table 3 provides information about fit indices and model fit for limit values as ideal fit values, acceptable values, incompatible and obtained values. According to the results, the obtained values are fit for the model.

\section{Discussion and Conclusion}

Within the scope of the study, a short form of Serious Leisure Inventory and Measure was created and its validity was ensured through the validity and the reliability analysis. The original form of Serious Leisure Inventory and Measure (SLIM), the basis of which was formed in James Gould's Phd dissertation, was developed by James Gould, DeWayne Moore, Francis McGuire and Robert Stebbins in 2008. The inventory is a 9-point Likert type, which consists of 72 items and 18 dimensions. The short form of the inventory is a 9-point Likert type, which consists of 54 items and 18 dimensions. At first, the inventory was designed with 72 items and analyzed in 6 sub-dimensions in terms of perseverance, leisure career, significant effort, durable outcomes, individual outcomes and identity with pursuit similar to Kim (2015). Then, through this inventory, the data was collected from 415 students at Southeastern University. Later, the data from 485 participants who participated in certain serious leisure activities were collected again to perform normality analysis and outliers were excluded from the analysis.

In the study, the findings of the short form of the tool with 54 items were also included. It was observed that the short form was valid and reliable. Fit indices for the form with 72 items ( $\mathrm{x} 2 / \mathrm{df}=1.53$; SRMR $=0.06$; RMSEA $=0.04 ; \mathrm{NNFI}=0.91 ; \mathrm{CFI}=0.91)$ and fit indices for the short form with 54 items $(\mathrm{x} 2 / \mathrm{df}=1.45$; $\mathrm{SRMR}=0.05$; RMSEA $=0.04 ; \mathrm{NNFI}=0.94 ; \mathrm{CFI}=0.95$ ) were determined as fit values (Gould et al., 2008). The exploratory and confirmatory factor analyses were at the level showing that both forms were validated similar to the short form of the serious leisure.

Serious leisure represents commitment and participation to leisure time activities to acquire and to express the required skills in order to perform the activities. Accordingly, another study conducted to analyze the psychometric properties and the construct validity of it in order to validate the serious leisure inventory and measurement tool (SLIM). For this analysis, 54-item version of SLIM was applied to 232 amateur athletes. Theoretical models proposed by Gould et al. (2011) were tested through confirmatory factor analysis (CFA) for the construct validity. The measurement model presented a very suitable fit index $\left(\chi^{2} / \mathrm{df}=3.29\right.$; GFI $=.97$; CFI $=.98$; SRMR $=.04$, RMSEA $=.05$; and internal reliability coefficients were between 71 and 86 . The model revealed a new three-factor structure that explained serious leisure gains sufficiently similar to our study findings $\left(\chi^{2} / \mathrm{df}=2.86\right.$; GFI $=0.92$, $\mathrm{CFI}=0.93, \mathrm{SRMR}=0.06, \mathrm{RMSEA}=0.078)$. The results of the study reveal adequate psychometric properties of 
SLIM and the possibility of its use as an indicator of serious leisure in sports (Romero, Iraurgi, \& Madariaga, 2017).

Another study to validate the serious leisure inventory aimed at testing 54-item measurement tool by applying it to 348 chess gamers and it was determined that the measurement tool named SLIM revealed acceptable fit value and value of validity. AFA findings, in which one third of the variance was explained, was evaluated by choosing 18 items with the highest item factor loads and functioning the best, and confirmatory factor analysis supported the findings with 18 items $(\mathrm{x} 2 / \mathrm{df}=1.68$, SRMR $=0.05$, RMSEA $=0.04, \mathrm{NNFI}=.90$ and CFI $=.91)$. Similar to the short form of SLIM in the study, the form with the best-functioning items was revealed, and 18 items functioning the best were found and the analysis provided evidence that the structure was validated (Gould et al., 2011).

Akgül, Ozdemir, Erturan Oğüt, and Karak Küçük (2016) put into practice Turkish adaptation of serious leisure inventory and measurement tool. It was carried out on 3 separate study groups of 474 students studying in various departments. During the adaptation process, the language equivalence of the SLIM was first examined and after it was found that it had language equivalence, validity and reliability analysis were performed. The construct validity of the adapted measurement tool was analyzed through confirmatory factor analysis and it was observed that it complied with the original form. As a result of the reliability analysis, the internal consistency coefficient of the scale was calculated as .97 and the test-re-reliability coefficient as .93. As a result of the item analysis, it was specified that total correlations of the corrected item of the sub-dimensions varied between .42 and .73 . These results show that the form is a valid and reliable measurement tool to measure serious leisure perspective. It is thought that the psychometric properties of the measurement tool brought into the Turkish literature within the scope of the study are validated and the introduction of the short form to measure the serious leisure measurement phenomenon will make an important contribution to the field as it is a commonly used measurement tool in the field. Personality congruence, perseverance / effort and durable outcomes sub-dimensions in the short form of the serious leisure inventory were extracted from the sub-dimensions in the original Turkish version of the measurement tool. 18 items were included in the short form, which was revealed as the best functioning items, but as a result of the analysis, the items imposed burden to each other were excluded and it was transformed into a 12item form, which consists of three sub-dimensions with the factor loads varying from .55 to .83 . The analysis showed that the form was validated.

In the other study, it was aimed at searching whether the different characteristics of serious leisure in Turkey are present or not and developing a valid and reliable Serious Leisure Inventory for serious leisure participants. As a result of exploratory and confirmatory factor analysis, the 9-factor form consisting of 42 items displayed acceptable validity and reliability results. In addition to the six sub-dimensions, two new dimensions emerged: personality congruence and sense of competence. In addition, the dimension of durable outcomes, which is one of the serious leisure features, is composed of two sub-dimensions as therapeutic outcomes and psycho-social outcomes. The item cutoff value was determined to be .32 in the study, which was lower than the value of .40.

Similarly, the data obtained from the short form of the Serious Leisure Inventory and Measurement Tool was tested in terms of the sample size $(.89 ; 2506.309, \mathrm{p}<0.001)$ and it showed that the sample size was sufficient for the factor analysis $(.94, \mathrm{p}<0.001)$. Unlike the findings of the study, it was observed that there were 9 components with an eigenvalue above 1 . It was observed that $66 \%$ of the total variance was explained similar to the percentage of the total variance $(65 \%)$ explained in 3 sub-dimensions in the short form of the tool. Moreover, the lowest factor load was .44, which demonstrates that it is valid considering the threshold as .32. Cronbach's Alpha reliability is .95 for the entire tool. The sub-dimensions in the created form were categorized as leisure career, self competence, psychosocial outcomes, therapeutic outcomes, unique ethos, identity, personality congruence, effort and individual outcomes. The confirmatory factor analysis validated the tool according to the specified criteria (RMSEA $=0.51$; $\mathrm{CFI}=0.98 ; \mathrm{NFI}=0.98 ; \mathrm{NNFI}=0.98 ; \mathrm{SRMR}=0.56$; AGF $=0.88 ; \mathrm{GFI}=0,89)$. It seems that serious and casual leisure measure (SCLM) is a valid and reliable tool to measure the level of participation to leisure as serious and casual leisure (Akyıldız Munusturlar \& Argan, 2016).

Another study which is present in the literature aimed at making adaptation and cultural adaptation of Serious Leisure Inventory and Measure (SLIM) and investigating the evidence related to construct validity of the tool. Confirmatory factor analysis was applied with 361 university students, which showed the 18 -factor model was sufficient and the fit indices close to those of the original article $\left(\chi^{2} / \mathrm{df}=1.95\right.$; CFI $=0.90$; RMSEA $=0.05$; SRMR $=0.05$ ). The internal reliability coefficients for the factors obtained varied between 0.73 and 0.94. SLIM Brazil was identified that it had satisfactory validity evidence. It is important to study with other age groups in terms of serious leisure through Portuguese version of the tool (Doll et al., 2018). It is also important to define the serious leisure perspective of different age groups and samples through the short form of serious leisure inventory expected to be an effective and efficient tool for Turkish population. Accordingly, a pool with 33 items, 16 of which was for serious leisure and 17 of which was for casual leisure, created to analyze the factors of serious and casual leisure in tourism. Two different samples were selected as in the short form of serious leisure inventory and it demonstrated that the serious leisure participation of the tourists was categorized into five factors according to the results of exploratory factor analysis. In this study, the measurement of the sufficiency of sample through KaiserMeyer-Olkin (KMO) resulted in 0.80 , which is lower than the study results. $64.20 \%$ of the total factor variance was explained similar to those of the findings of the study. Confirmatory factor analysis was performed by retesting and serious leisure participation provided an acceptable fit for the second data determined $(\chi 2 / \mathrm{df}=3.02$, SRMR $=$ $0.067, \mathrm{RMSEA}=0.073, \mathrm{NFI}=0.96, \mathrm{NNFI}=0.97, \mathrm{IFI}=0.98$ and $\mathrm{CFI}=0.98)($ Tsaur \& Huang, 2018).

Besides, the concept of serious leisure measurement has great importance in the literature, it is still required to study on serious leisure measurement for different sample groups. For this reason, a short form of serious leisure measurement was created and it was validated through validity and reliability analysis. In the scope of the study, the first data were obtained from 285 graduate students by using 18 items functioning the best in Turkish adaptation of the form. The sample size was determined as sufficient and a 3 dimensional structure were obtained through exploratory factor analysis. Moreover, cutoff value was determined as .40. As a result of extracting the items imposing burden each other, 12-item form was created from the measurement tool with 18 items in total. The factor loads of the new form consisting of the sub-dimensions such as identity with pursuit, perseverance and 
durable outcomes varied between .55 to .83 . The internal consistency coefficients for each sub-dimension are respectively $.83, .84$ and .75 besides the total variance explained as $65 \%$. The internal reliability coefficient for the total serious leisure measurement tool is .88 . Confirmatory factor analysis was performed to test the validity of the structure after the exploratory factor analysis and the retest data obtained from 350 students. As DFA fit indices were determined to be at an acceptable level after the test-retest, it seems to provide evidence of construct validity (RMSEA .069, SRMR 0.60, NFI 0.94, CFI 0.96, GFI 0.94, x2 / df 2.42). As a result, it is concluded that the short form of serious leisure inventory is a valid and reliable measurement tool. It is recommended to carry out studies on measurement of serious leisure in different sample groups, fields, organizations and culture to lead practitioners.

\section{References}

Akgül, B. M., Ozdemir, A. S., Erturan Oğüt, E. E., \& Karak Küçük, S. (2016). Serious leisure inventory and measurement: Validity and reliability study. Journal of Human Sciences, 13(2), 2820-2838.

Akyıldı, M. (2013). A "serious" view of leisure: serious leisure theory in leisure research. Pamukkale Journal of Sport Sciences, 4(3), 46-59.

Akyıldız Munusturlar, M., \& Argan, M. (2016). Development of the serious and casual leisure measure. World Leisure Journal, 58(2), 124141.Available at: https://doi.org/10.1080/16078055.2015.1126759.

Doll, J., Stigger, M. P., de Oliveira, S. N., de Souza, L. K., Pacheco, A. C., Anater, L. d. S. T., \& Sbicigo, J. B. (2018). Serious leisure inventory: cross-cultural adaptation and evidence of validity from the Serious Leisure Inventory and Measure (SLIM). Movimento (Esefid/Ufrgs), 24(4), 1139-1154.

Erkorkmaz, Ü., Etikan, İ., Demir, O., Özdamar, K., \& Sanisaoğlu, S. Y. (2013). Confirmatory factor analysis and fit indices: Review. Türkiye Klinikleri Journal of Medical Sciences, 33(1), 210-223.

Geoffrey, H. D., \& Currie, R. R. (1998). Cognitive dissonance: A consequence of serious leisure. World Leisure \&o Recreation, 40(3), 3641.Available at: https://doi.org/10.1080/10261133.1998.9674118.

Göklemen, T. Y. (2019). Investigation of individuals participating in archery sport in terms of serious leisure time. Akdeniz University Institute of Social Sciences, Sports Management Department, Master's Thesis, Antalya.

Gould, J., Moore, D., Karlin, N. J., Gaede, D. B., Walker, J., \& Dotterweich, A. R. (2011). Measuring serious leisure in chess: Model confirmation and method bias. Leisure Sciences, 33(4), 332-340.Available at: https://doi.org/10.1080/01490400.2011.583165.

Gould, J., Moore, D., McGuire, F., \& Stebbins, R. (2008). Development of the serious leisure inventory and measure. Journal of Leisure Research, 4O(1), 47-68.Available at: https://doi.org/10.1080/002222 16.2008.11950132.

Işık, U. (2014). Investigation of personality traits of serious leisure participants studying at school of physical education and sports. Dumlupınar University Institute of Health Sciences, Physical Education and Sports Department, Master's thesis, Kütahya.

Kim, M. L. (2015). Reinventory of the SLS: Development of SLSII. The Korean Journal of Physical Education, 54(2), 313-322.

Loughead, T. A. (1989). The use of leisure in career development. Journal of Career Development, 15(3), 154-163.Available at: https://doi.org/10.1177/089484538901500302.

Rojek, C. (1995). Decentring leisure: Rethinking leisure theory. London: Sage.

Romero, S., Iraurgi, I., \& Madariaga, A. (2017). Psychometric assessment of the Spanish version of the SLIM (Serious Leisure Inventory and Measure) in sports contexts. Sports Psychology Magazine, 26(2), 63-70.

Stebbins, R. A. (2016). Free time idea: Basic principles: Mehmet Demirel, Nurullah Emir Ekinci.

Stebbins., R. A. (1982). Serious leisure: A conceptual statement. The Pacific Sociological Review, 25(2), 251-272.

Stebbins.., R. (1992). Amateurs, professionals, and serious leisure. Montreal: McGill-Queen's University Press.

Stebbins..., R. (2001). New directions in the theory and research of serious leisure. Lewiston, NY: Edwin Mellen Press.

Tsaur, S.-H., \& Huang, C.-C. (2018). Serious tourists or casual tourists? Development and validation of a scale to measure tourists' serious/casual participation. Current Issues in Tourism, 2(23), $217-232$. 